\title{
Sinking Skin Flap Syndrome or Syndrome of the Trephined: A Report of Two Cases
}

\author{
Hae-Yeon Park, $\mathrm{MD}^{1}$, Sehee Kim, $\mathrm{MD}^{1}$, Joon-Sung Kim, MD, PhD ${ }^{1}$, Seong Hoon Lim, MD, PhD ${ }^{1}$, \\ Young Il Kim, $\mathrm{MD}^{2}$, Dong Hoon Lee, $\mathrm{MD}^{2}$, Bo Young Hong, $\mathrm{MD}, \mathrm{PhD}^{1}$ \\ Departments of ${ }^{1}$ Rehabilitation Medicine and ${ }^{2}$ Neurosurgery, St. Vincent's Hospital, \\ College of Medicine, The Catholic University of Korea, Seoul, Korea
}

Decompressive craniectomy (DC) is commonly performed in patients with intracranial hypertension or brain edema due to traumatic brain injury. Infrequently, neurologic deteriorations accompanied by sunken scalp may occur after DC. We report two patients with traumatic subdural hemorrhage who had neurologic deteriorations accompanied by sunken scalp after DC. Neurologic function improved dramatically in both patients after cranioplasty. Monitoring for neurologic deterioration after craniectomy is advised. For patients showing neurologic deficit with a sunken scalp, early cranioplasty should be considered.

Keywords Traumatic brain injuries, Decompressive craniectomy, Neurologic manifestations

\section{INTRODUCTION}

Traumatic brain injury (TBI) is one of the major causes of disability. After TBI, cognitive dysfunction, behavioral changes, seizures, metabolic dysfunction, and musculoskeletal dysfunction, such as spasticity, fracture, and heterotopic ossification can occur [1]. Decompressive craniectomy (DC) is commonly performed in patients with intracranial hypertension or brain edema due to TBI. In 2016, Kramer et al. [2] performed a cohort study with TBI patients. Among 644 patients, 51 patients (about 8\%) underwent DC. DC was performed when there was evidence of transtentorial herniation, worsening of midline shift, increased intracranial pressure, or loss of pupil light reflex. Complications that can arise after DC include hemorrhage, infections, and cerebrospinal fluid (CSF) disturbances [3].

After DC, cranioplasty is usually performed to improve cosmetic appearance, CSF hemodynamics, and for mechanical protection [3]. However, the optimal time between DC and cranioplasty has not been well established, and many studies have compared the efficacy of early cranioplasty ( 1 to 3 months after DC) with late cranioplasty (4 to 6 months after DC). One systematic review

Received June 20, 2018; Accepted August 21, 2018

Corresponding author: Bo Young Hong

Department of Rehabilitation Medicine, St. Vincent's Hospital, College of Medicine, The Catholic University of Korea, 93 Jungbu-daero, Paldal-gu, Suwon 16247, Korea. Tel: +82-31-249-7650, Fax: +82-31-251-4481, E-mail: byhong@catholic.ac.kr

ORCID: Hae-Yeon Park (http://orcid.org/0000-0002-7773-6329); Sehee Kim (http://orcid.org/0000-0002-9594-4463); Joon-Sung Kim (http://orcid. org/0000-0001-7457-593X); Seong Hoon Lim (http://orcid.org/0000-0002-5475-4153); Young Il Kim (http://orcid.org/0000-0001-6758-4344); Dong Hoon Lee (http://orcid.org/0000-0002-3796-8707); Bo Young Hong (http://orcid.org/0000-0001-9290-6173).

(c) This is an open-access article distributed under the terms of the Creative Commons Attribution Non-Commercial License (http://creativecommons.org/ licenses/by-nc/4.0) which permits unrestricted noncommercial use, distribution, and reproduction in any medium, provided the original work is properly cited. Copyright (C) 2019 by Korean Academy of Rehabilitation Medicine 
by Xu et al. [4] concluded that although early cranioplasty reduced the operation time, it increased the risk of complications. However, another systematic review by Tasiou et al. [5] concluded that early cranioplasty could lead to a better outcome.

Here, we report two cases of patients with traumatic subdural hemorrhage (t-SDH) who had neurologic deteriorations, accompanied by sunken scalp after DC. Neurologic function of both patients improved dramatically after early cranioplasty.

\section{CASE REPORTS}

This study was approved by the Institutional Review Board of the Catholic University of Korea, St. Vincent's Hospital, and informed consents were waived after IRB approval (No. VC16ZISE0066).
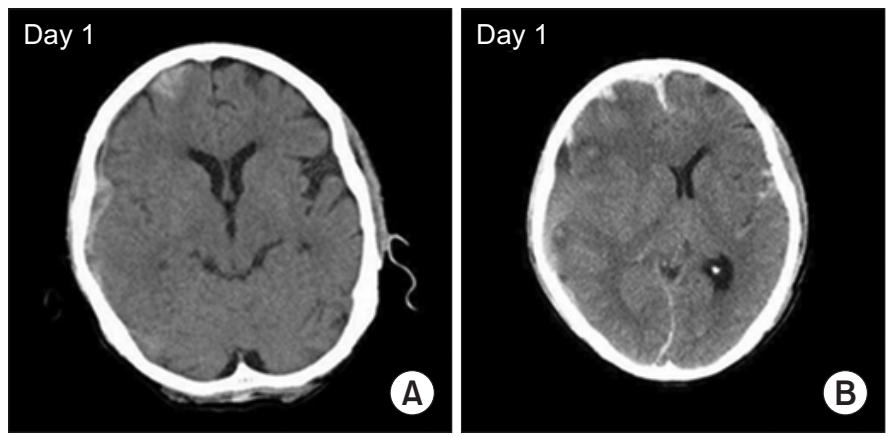

\section{Case 1}

A 66-year-old male patient came to the emergency department with headache after head trauma following syncope. Brain computed tomography (CT) revealed tSDH on the right frontotemporal lobe (Fig. 1A). A few hours later, he became drowsy and follow-up CT showed an increased amount of hemorrhage and midline shifting (Fig. 1B). DC was done that day, and motor power improved from Medical Research Council (MRC) grade 1-2 to grade 2-3. Seven weeks after the accident, however, he complained of shoulder pain, and his left arm weakness was aggravated to MRC grade 0-1. Brain magnetic resonance imaging (MRI) revealed midline shifting with a sunken scalp (Fig. 1C). Early cranioplasty was done (Fig. 1D) and motor power recovered to grade 3 in a week.

\section{Case 2}

A 68-year-old male patient was hospitalized after fall-

Fig. 1. Brain images of Case 1. (A) Traumatic subdural hemorrhage on the right frontotemporal lobe. (B) The follow-up brain computed tomography (CT) showing increased hemorrhage and midline shifting to the left side. (C) Magnetic resonance imaging showing midline shifting with sunken scalp of the right frontotemporal lobe. (D) Brain CT after cranioplasty.
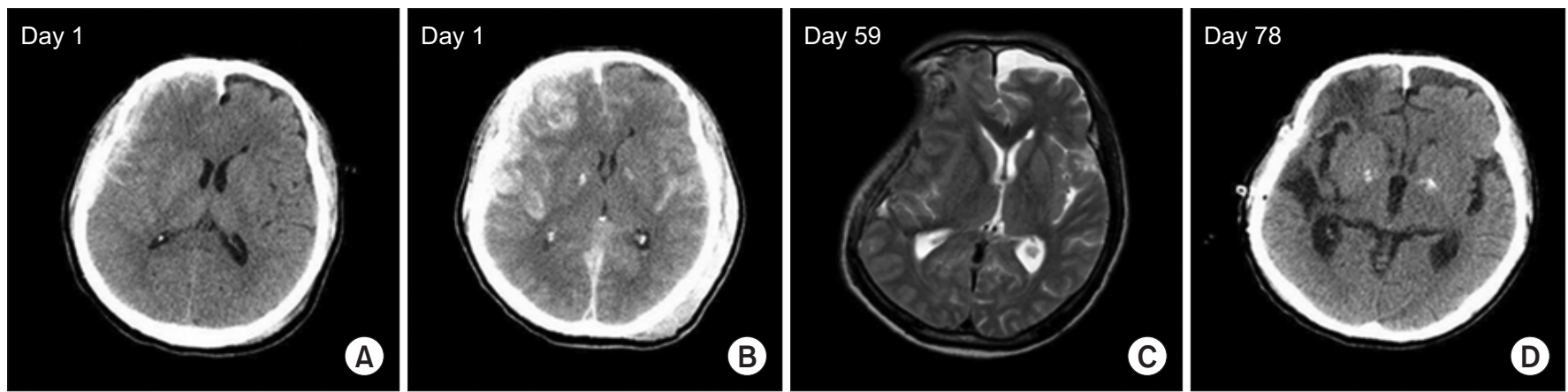

Fig. 2. Brain images of Case 2. (A) Traumatic subdural hemorrhage on the right frontotemporal lobe. (B) The follow-up brain computed tomography (CT) showing increased hemorrhage and midline shifting to the left side. (C) Magnetic resonance imaging showing midline shifting with sunken scalp of the right frontotemporal lobe. (D) Brain CT after cranioplasty. 
ing from a tree. The brain CT showed t-SDH on the right frontotemporal lobe (Fig. 2A), and 4 hours later there was an increased amount of hemorrhage and midline shifting (Fig. 2B). DC was done immediately, and he showed left hemiparesis with MRC grade 3. After 7 weeks, motor power improved to MRC grade 4 on the left side, but he complained of a headache in the right temporal area. A week later, his motor power decreased to MRC grade 1-2 on the left side. Diffusion MRI showed no acute infarction, but demonstrated midline shifting with a concave surface (Fig. 2C). Cranioplasty was performed 11 weeks after the accident (Fig. 2D), and motor power improved to MRC grade 3 on the fourth postoperative day.

\section{DISCUSSION}

Most DCs are performed in situations such as brain herniation or swelling after brain injury, and cranioplasty is performed after DC to cover the cranial defect for brain protection and for cosmetic reasons. Traditionally, surgeons prefer late cranioplasty, performed 3 to 6 months after DC, to control complications, such as swelling and infection. According to a systematic review comparing early and late cranioplasty, early cranioplasty did not show a significant advantage when compared with late cranioplasty [4]. Early cranioplasty reduced the duration of surgery, but was not effective in reducing post-cranioplasty complications, even resulting in a higher risk of hydrocephalus [4]. Salma et al. also supported delayed cranioplasty, because more bleeding complications occurred as a result of tissue fragility in patients with massive middle cerebral artery infarctions [6].

Sinking skin flap syndrome is defined as neurologic deficits with concave deformity and relaxation of the skin flap which tends to develop several weeks to months after large craniectomy [7]. In the two cases presented here, however, large cranial defects after DC resulted in a sunken scalp with neurologic deterioration. Following removal of the bone, atmospheric pressure on the cortex beneath the scalp can result in sinking skin, alterations in cerebral perfusion and flow of CSF, and neurologic deterioration, including motor weakness seen in our cases $[3,8,9]$. In both cases, motor weakness occurred with a sunken scalp and neurologic deterioration dramatically recovered following cranioplasty at 8 and 11 weeks after craniectomy, respectively. It is suggested, therefore, that clinicians should carefully monitor subacute TBI patients who have undergone DC.

Early cranioplasty is controversial. However, it not only has a cosmetic purpose, but a therapeutic purpose which can improve brain perfusion and CSF flow. Moreover, a recent retrospective study reported cognitive improvement after early cranioplasty [10].

When there is a rapid neurologic change in a patient with history of decompressive cranioplasty, CT should be performed first, before other less important tests. Furthermore, if a patient with sunken scalp shows any neurologic deterioration, it is important to recognize that this might be the cause of the neurologic change. Early cranioplasty should be performed when midline shifting is confirmed by CT, as in these cases, and can result in better outcomes.

Although there are published case reports [8] and studies $[5,9,10]$ on the usefulness of early cranioplasty for sinking skin flap syndrome, we present these case reports in order to emphasize the clinical importance of management in patients with rapid neurologic change after decompressive cranioplasty. As seen in our cases, dramatic improvements of neurologic recovery are possible after cranioplasty in patients showing neurologic deficits with sunken scalp. Therefore, patients should be closely checked for neurologic deteriorations after craniectomy, and if they show 'syndrome of the trephined, early cranioplasty should be considered.

\section{CONFLICT OF INTEREST}

No potential conflict of interest relevant to this article was reported.

\section{REFERENCES}

1. Masel BE, DeWitt DS. Traumatic brain injury: a disease process, not an event. J Neurotrauma 2010;27: 1529-40.

2. Kramer AH, Deis N, Ruddell S, Couillard P, Zygun DA, Doig CJ, et al. Decompressive craniectomy in patients with traumatic brain injury: are the usual indications congruent with those evaluated in clinical trials? Neurocrit Care 2016;25:10-9.

3. Kurland DB, Khaladj-Ghom A, Stokum JA, Carusillo B, Karimy JK, Gerzanich V, et al. Complications associ- 
ated with decompressive craniectomy: a systematic review. Neurocrit Care 2015;23:292-304.

4. Xu H, Niu C, Fu X, Ding W, Ling S, Jiang X, et al. Early cranioplasty vs. late cranioplasty for the treatment of cranial defect: a systematic review. Clin Neurol Neurosurg 2015;136:33-40.

5. Tasiou A, Vagkopoulos K, Georgiadis I, Brotis AG, Gatos H, Fountas KN. Cranioplasty optimal timing in cases of decompressive craniectomy after severe head injury: a systematic literature review. Interdiscip Neurosurg 2014;1:107-11.

6. Salma A, Abou Al-Shaar H, Hassounah M. Letter to the Editor: Cranioplasty complications and the timing of surgery. J Neurosurg 2016;124:280-1.
7. Yamaura A, Makino H. Neurological deficits in the presence of the sinking skin flap following decompressive craniectomy. Neurol Med Chir (Tokyo) 1977; 17(1 Pt 1):43-53.

8. Jeyaraj P. Importance of early cranioplasty in reversing the "syndrome of the trephine/motor trephine syndrome/sinking skin flap syndrome”. J Maxillofac Oral Surg 2015;14:666-73.

9. Annan M, De Toffol B, Hommet C, Mondon K. Sinking skin flap syndrome (or syndrome of the trephined): a review. Br J Neurosurg 2015;29:314-8.

10. Kim BW, Kim TU, Hyun JK. Effects of early cranioplasty on the restoration of cognitive and functional impairments. Ann Rehabil Med 2017;41:354-61. 